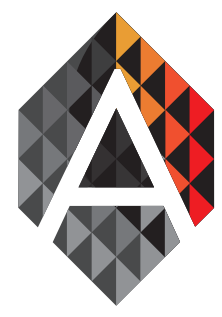

\title{
Collaborative Computer-Assisted Cognitive Rehabilitation System
}

\author{
Miguel Oliver ${ }^{\mathrm{a}}$, José Pascual Molina ${ }^{\mathrm{a}, \mathrm{b}}$, \\ Antonio Fernández-Caballero ${ }^{\mathrm{a}, \mathrm{b}}$ and Pascual González $\mathrm{z}^{\mathrm{a}, \mathrm{b}}$ \\ aUniversidad de Castilla-La Mancha, Instituto de Investigación en Informática de Albacete, 02071-Albacete, \\ Spain \\ bUniversidad de Castilla-La Mancha, Departamento de Sistemas Informáticos, 02071-Albacete, Spain
}

\begin{tabular}{|c|c|}
\hline KEYWORD & ABSTRACT \\
\hline $\begin{array}{l}\text { Cognitive } \\
\text { Rehabilitation; } \\
\text { Multiuser } \\
\text { System; Social; } \\
\text { Videogames; } \\
\text { Kinect; Assistive } \\
\text { Technologies }\end{array}$ & $\begin{array}{l}\text { Recently have been proposed different physical and cognitive rehabilitation system } \\
\text { that allow people with some disabilities to improve and recover some lost capabili- } \\
\text { ties. All these systems allow to carry out these therapies at home proving patients the } \\
\text { possibility to accomplish a better rehabilitation, due to the fact that they can practice } \\
\text { at home and in a more controlled environment. But, it is not so common that these } \\
\text { systems include some social features that reduce the feeling of social isolation of the } \\
\text { patients. Thus, in this paper we present an adaptation of a previous proposal including } \\
\text { some multiuser therapies that try include some social features and other aspect related } \\
\text { to videogames that increases the motivation and makes the treatment funny. }\end{array}$ \\
\hline
\end{tabular}

\section{Introduction}

The growth in the life-span of people is increasing the needed of offering new technological solutions that allow them to live a better old age. This aging affects the perception and also includes some cognitive and physical problems. As Ballesteros notice (Ballesteros et al., 2015), there are evidences that the physical activity, cognitive training and social engagement improve the quality of life and reduce cognitive decline in older adults. To provide solution that could improve the quality of life of these people the assistive technologies bring technological solutions that allow people to improve or reduce the effect of their disabilities, offering the new ways of rehabilitate their lost capabilities. In general, the rehabilitation process can be physical (affecting the movement of bones and joints) or cognitive (affecting brain processing), so the technological solutions should include systems that combine therapies related to these problems. But, we must take into account other troubles associated with the aging such as the loss of abilities in the perception of external stimuli. Thus, although these technological proposals are showing high potential in the rehabilitation process, promoting engagement with rehabilitation and make easy to deploying it into the home (Smith et al., 2012), all these proposals must take into account all the problems mentioned above and mainly those related to the social problem. In this case, as Cranen indicate (Cranen et al., 2012), after carrying out a study of the patients' perceptions regarding prospective tele-rehabilitation services, «some patients reflected negatively on the compatibility construct as they thought telerehabilitation would lead to social isolation». Moreover, participants of this study also indicated that patients who did not consider themselves as self-disciplined, found it was important to be motivated by others,

Miguel Oliver, José Pascual Molina,

Antonio Fernández-Caballero and Pascual González

Collaborative Computer-Assisted

Cognitive Rehabilitation System
ADCAIJ: Advances in Distributed Computing and Articial Intelligence Journal Regular Issue, Vol. 6 N. 3 (2017), 57-74 eISSN: 2255-2863 - http://adcaij.usal.es ( ) Ediciones Universidad de Salamanca - cC BY 
training in groups. Finally, in this study the users of tele-rehabilitation systems also highlight the important role of the therapist, because sometimes «Patients felt insecure about their own exercise abilities and were afraid something would go wrong in absence of the face-to-face supervision of a therapist». Thus, the new rehabilitation systems must include solutions that reduce this social isolation feeling, introducing some features that allows the patients to stablish social relationships with other patient. Furthermore, these systems must provide tools that connected the patient and the therapist in an adequate way, offering a similar assistance to the way these treatments are carried out in a specialized medical center.

Although, it is not so common find solutions that include multiusers collaborating in the fulfilment of a therapy, the inclusion of this feature improves the social aspect of the rehabilitation process. It allows the user being in touch with other users at the same time that he/she carries out a specific therapy and, as Ballesteros stated (Ballesteros et al., 2015), the increased social engagement in older adults is associated with greater quality of life. In addition, as Griffiths stated (Griffiths, 2005), video games have been shown to provide therapeutic benefits in many contexts. Moreover, Griffiths and other colleagues (Griffiths et al., 2004), after conducting a survey of 540 Everquest players, found that the favorite features of this game were the social aspects of playing online, such as social contact, and helping others.

This paper presents an improvement of a previous system (Oliver et al., 2016) designed to aid in the cognitive and physical rehabilitation of elderly people, combined in one therapy these two disabilities. The main advantage of the system presented now in this paper is the inclusion of multiuser execution and some game features. In our tele-rehabilitation system, one therapy could be carry out by several users simultaneously. In this case, using a multiuser execution, it is not possible to carry out a therapy in an isolate way, several users should collaborate to successfully conclude it. In addition, the inclusion of same features associated with videogames increases the motivation and make the rehabilitation process more fun.

The contents of this paper is structured as followed. After reviewing the assistive technologies used in cognitive and physical rehabilitation, we present the new proposal. First we describe the general aspect of the system, its architecture and the cognitive therapist supported. After that, we present our multiuser solution. This proposal allows the therapist to define two different strategies to carry out the therapy: collaboration or competition. Next, we describe our multisensory proposal explaining how the therapist can configure the therapy to include several senses cues enhancing the possibilities to use our system by visually impaired people. Finally, we include some conclusion and future works.

\section{Assistive Technologies in Rehabilitation}

Assistive technologies attempt to bring technology to people allowing them to carry out some task that they could not achieve without this assistance. More and more, the use of technology is applied in all human activities, offering people some support and facilitating their completion, and rehabilitation cannot stay out of this trend. In this case, the use of technology in the rehabilitation domain offers not only the possibility to control the execution of the rehabilitation activity, but also, it allows carrying out these activities without the presence of the therapist. Moreover, the patients can carry out these activities not only in the hospital but also in their houses allowing them to practice more time and so improving their rehabilitation.

In any case, move the rehabilitation activities to unsupervised spaces, where the therapist does not control the rehabilitation activity, is not only achieved by implementing systems that control the correct execution of some specific task. It is needed the inclusion of some expert system that allows monitoring the execution, achieving an effective rehabilitation, and preventing some healthy problems that the use of these systems in an unsupervised environment could cause.

\subsection{Assistive Technologies in Physical and Cognitive Rehabilitation}

The emergence of new devices such as Kinect and other depth cameras has promoted the development of systems that try to offer new solution to the physical rehabilitation domain. Nowadays there are several research proposals (Chang et al., 2011; Freitas et al., 2012; Oliver et al., 2014) that include this device in their solutions.

Miguel Oliver, José Pascual Molina,

Antonio Fernández-Caballero and Pascual González

Collaborative Computer-Assisted

Cognitive Rehabilitation System
ADCAIJ: Advances in Distributed Computing and Articial Intelligence Journal Regular Issue, Vol. 6 N. 3 (2017), 57-74 eISSN: 2255-2863 - http://adcaij.usal.es (c) Ediciones Universidad de Salamanca - CC BY 
In addition, there are also application proposed by some public institutions, with the collaboration of relevant companies such as Accenture or Indra, (KineLabs, 2016; TeKi, 2016; Toyra, 2016) that deliver their solutions sometimes as free software. Furthermore, we can find commercial systems such as those proposed by Vera or VirtualRehab (Vera, 2016; VirtualRehab, 2016) that include Kinect sensors to create physical rehabilitation solution. Finally, there are also studies (Pyae et al., 2015) that analyze the perception of older people about the usability of commercial games used for improving the physical activity and they conclude that these users recommended Kinect as the most effective interaction. Thus, we can conclude that the use of Kinect to create physical rehabilitation system is now widely accepted.

In the event of patients that suffer cognitive impairments, there are also systems that help them in the rehabilitation process. Users who make use of these rehabilitation systems are people who need to recover lost cognitive abilities. This may be due by the degradation resulting from age, or from an injury or stroke that affects their cognitive abilities. It is impossible to define a unique way of dealing with these problems. This is due to the multitude of cognitive deficits and shortcomings that occur in the human brain, as well as the variety of ways in which they are presented. Each type of brain disorder requires different methods and specialists for their treatment (Montero et al., 2011)

Among the systems that can be used for the treatment of cognitive problems, we emphasize the software for neuropsychological rehabilitation of cognitive impairment named Gradior (Gradior, 2016) that is intended for people with traumatic brain injury, schizophrenia or dementia. The JClic system (JClic, 2016) is another example oriented towards primary education patients. Meanwhile, Bungalow Software and Learning Fundamentals (Bungalow Software, 2016; Learning Fundamentals, 2016) are software programs for the rehabilitation of language.

In fact, cognitive rehabilitation is a field in which continuous research is conducted, offering several proposals that try to provide solution to severe cognitive problems. A recent example is a multisensory treatment for people with space hemineglect (Teruel et al., 2015), people that suffer a deficit in attention to and awareness of one side of space, mainly the left side. In this proposal the therapist can choose the use of different stimuli (visual, auditory and haptic) to help the user in realizing that an object is approaching to him/her, overstimulating the patient senses to improve their perception. Another example is the HABITAT system (Montero et al., 2011), developed to assist people with acquired brain injury (ABI). This proposal provided a classification of activity patterns that are used in the relearning process. This study also concludes that computer-based treatment is especially accepted by younger people, increases the motivation of the patient, and reduces the activity completion time.

Although the use of Kinect to control the patients' movements in a cognitive rehabilitation therapy is not so frequent, we can find some examples. One of the first proposal is the Tango: $\mathrm{H}$ system (Tangible Goals: Health) (González et al., 2013) that focuses on hospitalized children with disabilities. It offers some funny games in which the children must use some body parts to select the object that allow them to achieve the correct answer. With a similar proposal but in the domain of older people rehabilitation, Saenz de Urturi present a system that use Kinect to improve the memory by performing mental activities and physical exercise at the same time (Saenz de Urturi et al., 2012). They create several exercises of different level of complexity to be adapted depending of the mental state of the patient. Moreover, in other study they analyze the effectiveness of this rehabilitation therapy and they conclude that, although this evaluation did not show an improvement of the cognitive impairment measured by the MMSE, the impairment is maintaining, that is, the cognitive performance is not declining and its progression is slow (Saenz de Urturi et al., 2014). Other more recent proposal is presented by Desai (Desai et al., 2016), where they present a system for the rehabilitation of stroke affected patients that includes four immersive games. One of them is a quiz activity, which not only makes the person perform the physical exercise, but also focuses on cognitive aspect to answer some basic set of general knowledge questions. Finally, we can find the proposal presented by us which is the base of this work (Oliver et al., 2016) that. In that paper a tool for designing cognitive therapies is presented. This tool allows the therapists to design on scratch their own cognitive therapies associated with pair and multiple association or categorization exercises. This capability to design their own exercises allows the therapists to adapt their therapies to each specific patient. In addition, these cognitive exercises are joint with physical movement of the patient combining the cognitive and physical rehabilitation in one therapy.

Miguel Oliver, José Pascual Molina,

Antonio Fernández-Caballero and Pascual González

Collaborative Computer-Assisted

Cognitive Rehabilitation System
ADCAIJ: Advances in Distributed Computing and Articial Intelligence Journal Regular Issue, Vol. 6 N. 3 (2017), 57-74 eISSN: 2255-2863 - http://adcaij.usal.es (c) Ediciones Universidad de Salamanca - cC BY 


\section{Proposed Cognitive Rehabilitation System}

The proposed system combines cognitive rehabilitation with physical exercises. In addition to exercising the brain, the user also exercises the body for completing his/her rehabilitation.

The system attempts to cognitive rehabilitation of people. To achieve this an open rehabilitation system has been created, in which the therapist can create rehabilitation exercises from scratch. This allows them to create exercises based on well-known therapies and adapted to a specific patient. Creating exercises based on well-known therapies produces two advantages. On the one hand, the rehabilitation exercise has been verified by other therapists and specialists, so they have evidence of the advantages and disadvantages of each type of therapy and exercise. On the other hand, creating exercises with well-known therapies allows the therapist to compare the results with experiments already performed, and apply formulas already created and tested to determine the progress of their patients.

The rehabilitation specialist creates each therapy, based on existing literature and the particular nature of each patient. Based in the proposal of Rodríguez (Rodríguez et al., 2016), a Therapy is defined as a set of Activities created to rehabilitate a specific cognitive impairment. Each Activity can be divided into elemental Tasks and each Task is defined as a sequence of Steps. In our case we associate the concept Exercise to the Task.

The therapist can define some rules that control the evolution from one exercise to another. To create these rules, the therapists can define fuzzy variables, such as fatigue, stress, and so on, that control the flow of the exercises signed by the therapist. All these rules are the knowledge base of the system to decide, at runtime, which is the best transition between the available ones, i.e. which is the most desirable next action that a user should make while he/she is performing a Task or an Activity.

Each exercise consists of a series of elements that have a specific meaning that patients should recognize and carry out a specific cognitive process such as association, categorization, and so on. To create the exercise in the virtual world the therapist locates some elements inside it, these elements may represent concepts or real-world. The specialist locates as many elements as he/she wants and selects some features, such as size, position, orientation and color.

When the patient wants to carry out the exercise, he/she should be located in front of a Kinect sensor that captures his/her figure. This figure and the elements defined by the therapist appear on the monitor. In addition, in the screen also appears all the instructions that guide the patient in the performance of the exercise. The patient's mission is to select several elements on the screen taking into account a specific order defined by the therapist. To select each element, the patient places a particular body part on it. The allowed parts of the body used to select an element is stabilized by the therapist when the exercise is created.

\subsection{Exercise Types}

Currently, the system allows developing three types of exercises: Pair Association, Multiple Association, and Categorization. These exercises have been selected due to the fact that they are widely applied in the rehabilitation of many cognitive deficits of the front executive function of the brain. In addition, the system offers a kind of free exercise, in which the therapist can design other types of exercises by defining freely all the options. The interface for the selection of exercises is shown in Figure 1.

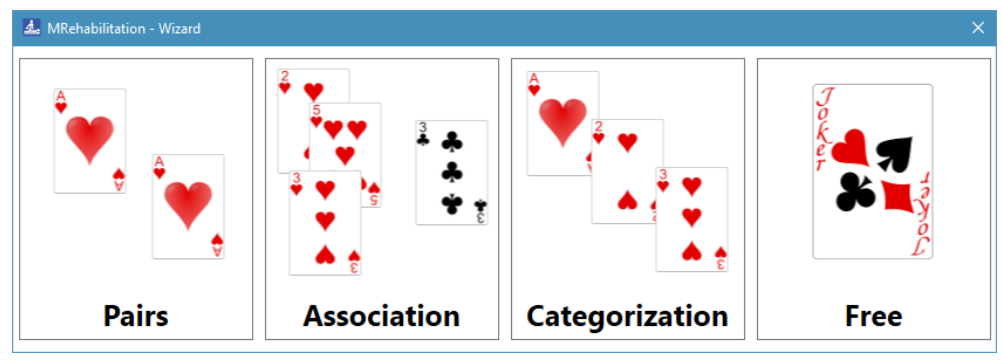

Figure 1. Type of exercise selection interface

Miguel Oliver, José Pascual Molina,

Antonio Fernández-Caballero and Pascual González

Collaborative Computer-Assisted

Cognitive Rehabilitation System
ADCAIJ: Advances in Distributed Computing and Articial Intelligence Journal Regular Issue, Vol. 6 N. 3 (2017), 57-74 eISSN: 2255-2863 - http://adcaij.usal.es (c) Ediciones Universidad de Salamanca - CC BY 
The patient should perform different actions depending on the type of exercise selected. Specifically, depending of the exercise designed by the therapist, the patient should carry out the next action:

- Pair Association: The patient must select pair of elements with similar features or meaning.

- Multiple Association: The patient must select the elements that belong to a particular group.

- Categorization: The patient must sort accordingly to a specific criterion the displayed elements.

- Free: In this case, the patient should carry out the exercises freely designed by the therapist, who define the rules of each exercise. For example, the therapist could create an exercise in which the patient should select several trio of elements instead of pair, such as in the case of the pair association.

\subsection{System Architecture}

The diagram of components describing the architecture of the system is shown in Figure 2, as can be seen there are two main components: Therapy Design and Therapy Execution Environment. The first one, Therapy Design component is handled exclusively by the therapist, as he/she is in charge of designing a particular therapy for each patient. This component allows the therapists to design a specific therapy, with their activities, tasks and steps. In addition, they could define fuzzy rules to manage the flow, i.e. the rule that should be applied to determine which activity, task which or step should be the next one after finishing the current one. The Therapy Design component is made up of four new components: Therapy Authoring; Rule Authoring; Physical Exercise Authoring; and Cognitive Exercise Authoring. The first one, Therapy Authoring allows the therapist to create and modify therapies, activities and task planned for each patient. This component used the design proposed in the work of Rodríguez (Rodríguez et al., 2016). The next component, Rule Authoring is responsible for controlling the rehabilitation process. The difficulty and accuracy of each exercise, as well as the next stage of the rehabilitation process, are determined through controlling some specific variables of the exercise and the vital signs of the user, such as those proposed in (Hernandez et al., 2015). As in the previous one, this component used the design describe in the article written by Rodríguez (Rodríguez et al., 2016). The next two components allow designing the specific steps of a particular exercise. Our system provides two types of rehabilitation exercises: physical; cognitive and physical. The design of each type of exercise is managed by Physical Exercise Authoring and Cognitive Exercise Authoring respectively. Physical Exercise Authoring component (Oliver et al., 2014) makes the design of physical rehabilitation exercises possible. It allows the therapists to design two type of exercises, defining a specific corporal position or a body gesture. A deeper description of this component could be seen in our previous work (Oliver et al., 2014). The last component, Cognitive Exercise Authoring, allows the specialist to create cognitive exercises combined with a physical movement. This component will be presented below.

Miguel Oliver, José Pascual Molina,

Antonio Fernández-Caballero and Pascual González

Collaborative Computer-Assisted

Cognitive Rehabilitation System
ADCAIJ: Advances in Distributed Computing and Articial Intelligence Journal Regular Issue, Vol. 6 N. 3 (2017), 57-74 elSSN: 2255-2863 - http://adcaij.usal.es (c) Ediciones Universidad de Salamanca - CC BY 


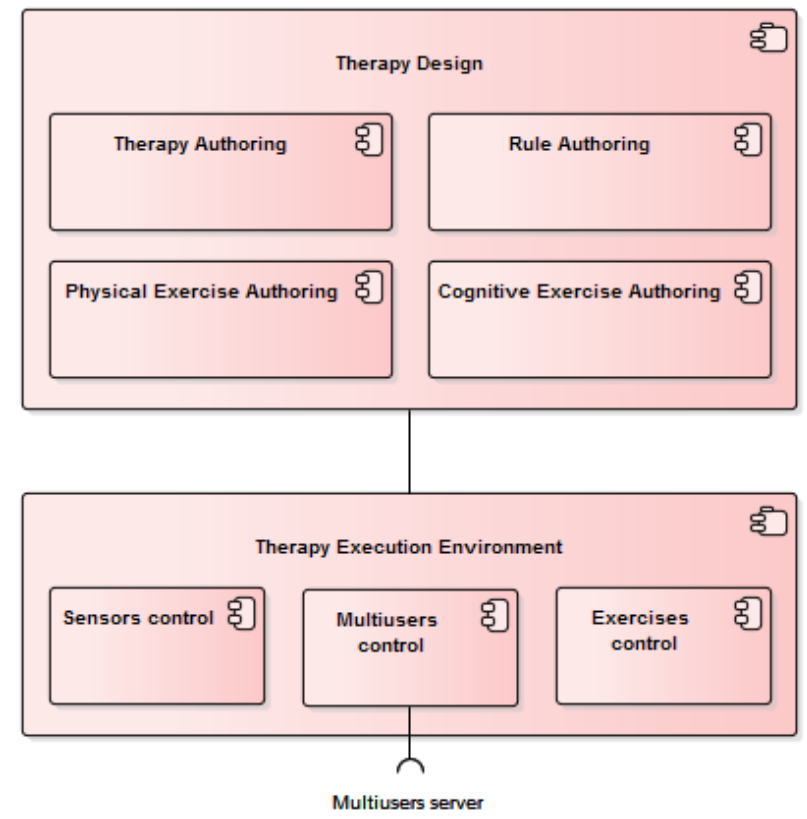

Figure 2. System architecture

On the other side, Therapy Execution Environment component is responsible for controlling user's movements through the system sensors by the component Sensors control, as well as the execution of rehabilitation exercises by the component Exercises control. Our system make use of several Kinect sensors to achieve a more accurate information of the real movement of the patient, who can freely move in the interaction space, where the rehabilitation takes place. Thus, Sensors control component gathers all the data produced by each Kinect sensors and merges their data to achieve the correct date of the patient's joins. Thus, the system presents the user-data to other system's modules in a unified way. Further, the multiuser rehabilitation is controlled by the Multiusers control module. This module connects to a server and provides exercise performance by multiple users. The network architecture supported by this module, as well as the available rehabilitation modes, will be shown below.

\section{Cognitive Exercises Authoring}

The specialist is responsible for designing a specific therapy for a particular patient. Through the Therapy Authoring component, the therapist can design the structure of a therapy, by defining activities, tasks and, finally, the Cognitive Exercise Authoring component allows the therapist to design all the steps of a specific task or exercise.

\subsection{Design of cognitive-physical therapies}

When the specialist creates a new exercise, the four types of exercises supported by the system appear (see Figure 1). After selecting the desired type, the exercise edition screen is displayed (see Figure 3). This screen is divided into five areas. At the bottom, appears the objects than the therapist can use to design the exercises, in this case the possible objects are animals. Just by clicking on each animal will appear an element in the working area. In this case, due to the fact that the exercise chosen is Pair Association, when use select the image of one animal at the bottom of the screen, two elements with this image appear in the working area. At the top, the therapist can introduce the name and the goal of the exercise. These labels should be descriptive enough since the patient can understand what he/she should carry out to solve the exercise successfully. In the left side of

Miguel Oliver, José Pascual Molina,

Antonio Fernández-Caballero and Pascual González

Collaborative Computer-Assisted

Cognitive Rehabilitation System
ADCAIJ: Advances in Distributed Computing and Articial Intelligence Journal Regular Issue, Vol. 6 N. 3 (2017), 57-74 eISSN: 2255-2863 - http://adcaij.usal.es (c) Ediciones Universidad de Salamanca - CC BY 
the screen, the objects already located in the working area appear. Finally, the right side of the screen shows the Steps that make up the exercise. An exercise may consist of one or more Steps. In each Step the elements displayed can be totally different from the rest of the others Steps.

There are three types of elements that can be added to an exercise (valid, distracting or prohibited). These elements are used to create complex exercises that require the patient to make an additional cognitive or even physical effort.

- Valid elements. Elements with which the user must interact. The therapist will put these elements to create the exercise. All valid elements must be turn on to complete the exercise. Activating one of them will be a point for the user.

- Distracting elements. Elements placed to distract the patient. The therapist places these elements to add cognitive complexity to the exercise, since the more elements exist in the exercise, the more cognitive effort the patient requires. Each time the user turns on one distracting element, an error message appears and it is counted as a cognitive error

- Prohibited elements. Elements that represent areas where the user cannot enter with the parts of the body selected by the therapist. The therapist places these elements to prevent the user to move through an area, thereby increasing physical complexity of the exercise. If the patient enters in one prohibited element, an error message appears and it is counted as a physical error.

For improving the adaptation of the system to different user and therapies, the therapist can choose the collection of images used in each exercise. Ones the therapist has chosen a specific element of those showed at the bottom of the screen, it appears in the working area and the therapist can change its location, its size or its orientation, as can be seen in Figure 3. Thus, the therapists can design their own therapies as they need, providing all the features needed to personalize each exercise.

The selection of objects must be made as simple as possible for the patient. In this way, to select an element, the patient must position a part of his/her body on the element, and maintain the location for at least 1 second. Thus, the therapist should define, for each element, the body part that the patient should use to select each one. As our system makes use the first version of the Kinect sensor to control the movements of the patient, the therapist can choose any of the joints that this device controls. In Figure 4, we show the joint managed by our system. All these options enable the specialist to design an exercise as he/she wishes. But for providing some support in the design process, there are some options pre-set for each type of exercise. So, the therapist just needs to change as little as possible.

Miguel Oliver, José Pascual Molina,

Antonio Fernández-Caballero and Pascual González

Collaborative Computer-Assisted

Cognitive Rehabilitation System
ADCAIJ: Advances in Distributed Computing and Articial Intelligence Journal Regular Issue, Vol. 6 N. 3 (2017), 57-74 eISSN: 2255-2863 - http://adcaij.usal.es (c) Ediciones Universidad de Salamanca - cC BY 


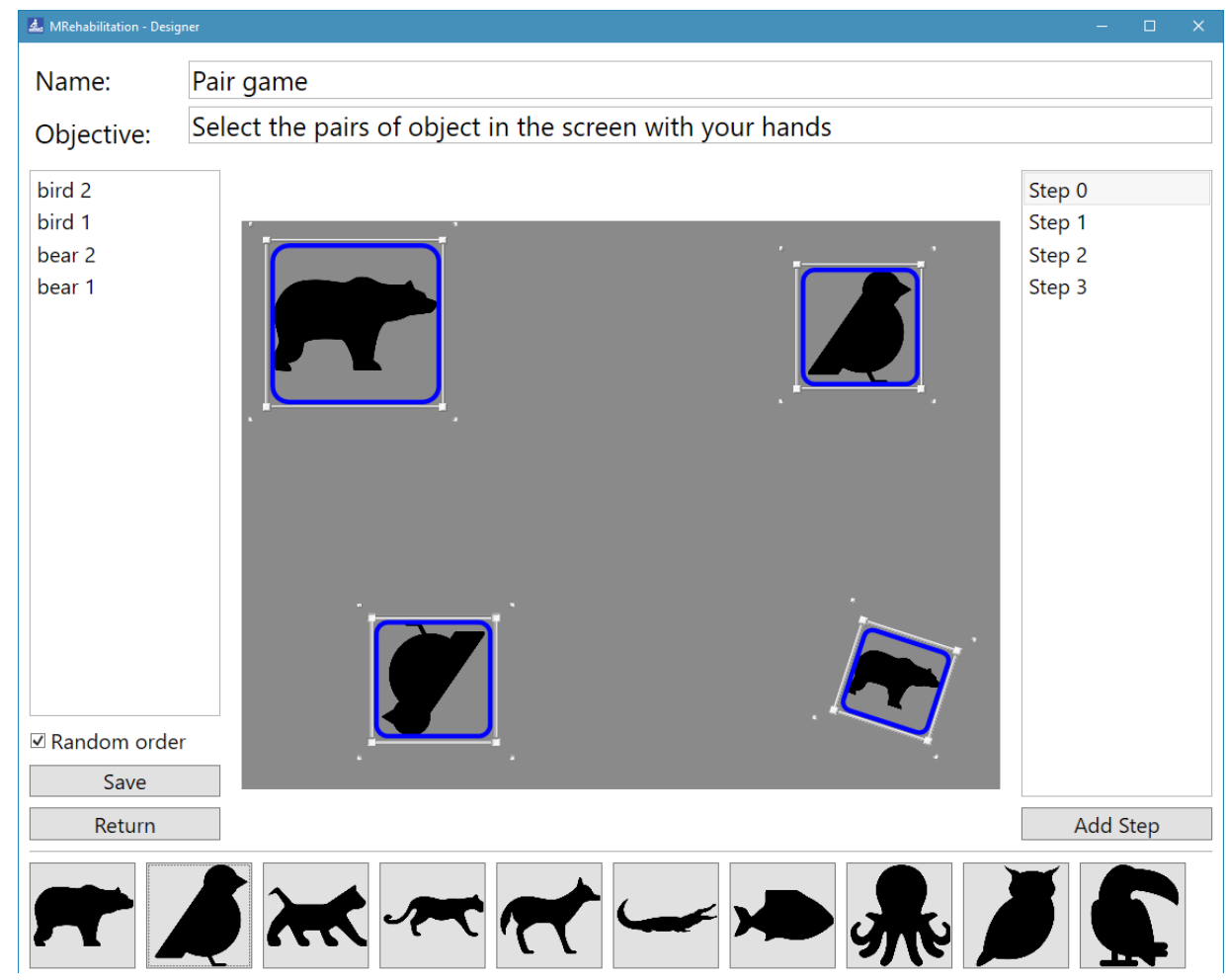

Figure 3. Exercise edition interface

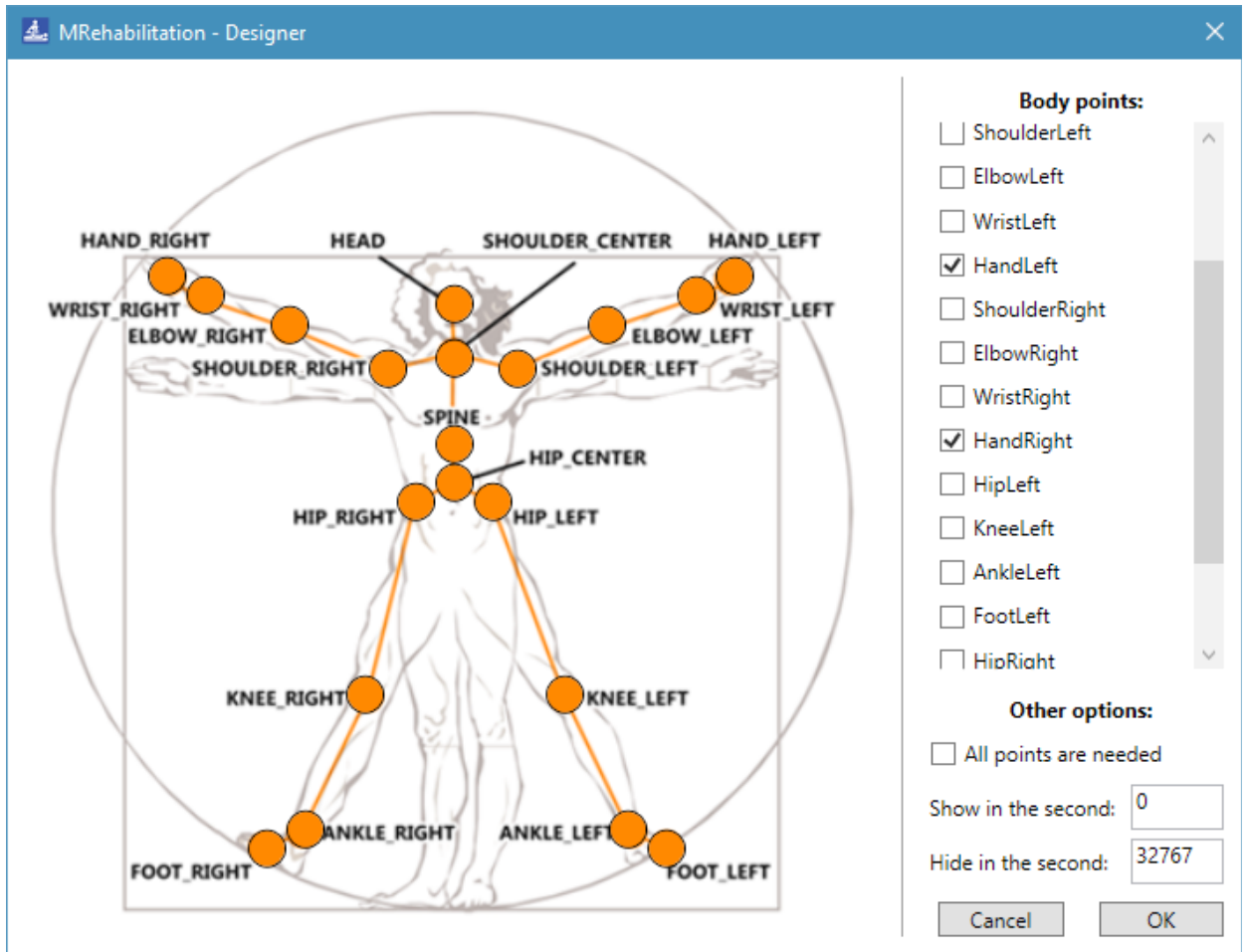

Figure 4. Feedback options for an object

Miguel Oliver, José Pascual Molina,

Antonio Fernández-Caballero and Pascual González

Collaborative Computer-Assisted

Cognitive Rehabilitation System
ADCAIJ: Advances in Distributed Computing and Articial Intelligence Journal Regular Issue, Vol. 6 N. 3 (2017), 57-74 eISSN: 2255-2863 - http://adcaij.usal.es (c) Ediciones Universidad de Salamanca - CC BY 
In addition, Figure 4 shows other options that can be used in each of the objects added by the therapist. The All points are needed option indicates that the object will be selected at the time that all selected body points are inside it. In this way we can create an object that is activated when several areas of the body are selecting it, e.g. an object that has to be selected with both hands. We also have the option to show and hide an object at a particular time. Option Show in the second indicates when the object will be displayed to the user, and option Hide in the second indicates when the object will be hidden. If there is an object that has not been shown the user, the user can not complete the rehabilitation exercise, because he/she has to interact with more objects. But instead, if the object has been shown to the user and has been hidden later, it is considered as a failure for the user, because he/she has failed to activate it in the time available for it, and therefore the object will not prevent the end of the exercise.

\subsection{Design of Multiuser Therapies}

To improve rehabilitation of patients, increasing the interest of users for their own rehabilitation, and providing a new social environment, a multiuser rehabilitation system has been proposed. This system includes two action modes for carrying out the rehabilitation exercise: collaborative or competitive. The inclusion of these two modes allows the therapist to design different social strategies and lets him/her analyze other relevant aspects such as the communication and coordination between the patient and other users that work with him/her to accomplish the exercise. At the same time the participation of several people in the exercise reduce the feeling of isolation of the patient, loneliness, increasing the social engagement that, as Ballesteros noticed (Ballesteros et al., 2015), it is one of the features needed to improve the quality of life and to reduce cognitive decline in older adults. Finally, the use of multiuser exercises reinforces the user perception of the rehabilitation process as game, introducing all the benefits of using games in any learning activity.

In the first case, the collaborative mode, the patient need the support of other user (another patient or perhaps the therapist) to carry out a specific exercise. In this case, the patient is not able to successfully complete the exercise without the participation of other user. The patient need to coordinate and communicate with other user to organize the actions needed to accomplish the exercise. As we previously mentioned this action mode allow the therapist to evaluate other relevant aspects needed to improve patient's social skills.

The second action mode, competitive mode, provide other relevant features to our system. First, the patient could learn from the actions carried out by the other user, because he/she can see how the other user fulfill the same exercise. Moreover, with the inclusion of this feature we introduce some aspects of social games, that, as Cagiltay indicate (Cagiltay et al., 2015), «competition in games enhanced learning and motivation of the participants».

\subsubsection{Competitive exercise}

Competitive exercises are those in which each user competes against another to overcome him/her. As we mention before, this type of exercises could motive the patient to carry out the rehabilitation process in a better way. In addition, the patients can share their experience with other patients and learn from other users since they can see the actions that other users are performing. For this reason, rehabilitation exercises can be very helpful for the therapist, because in this way he/she could teach patients how they should perform the rehabilitation correctly. In this case, the therapist could play at the same time and can guide the patient in carrying out the exercise.

Our system manages five types of competitive exercises: Competitive Share Elements; Competitive Time; Competitive Cognitive Errors; Competitive Physical Errors; Competitive Errors Count. All these types of exercises will be presented below.

\section{Competitive Share Elements}

In this type of exercise, patients share the elements showed in the working area. The elements showed in the working area of both patients are the same and if an element is selected by one patient it cannot be selected by the other. The winner of this type of exercise is the user who selects more objects. The exercise may be the

Miguel Oliver, José Pascual Molina,

Antonio Fernández-Caballero and Pascual González

Collaborative Computer-Assisted

Cognitive Rehabilitation System
ADCAIJ: Advances in Distributed Computing and Articial Intelligence Journal Regular Issue, Vol. 6 N. 3 (2017), 57-74 elSSN: 2255-2863 - http://adcaij.usal.es (c) Ediciones Universidad de Salamanca - cC BY 
same as the patient would perform individually, so it does not require any additional changes in the way the therapists design an exercise.

\section{Competitive Time}

In this type of exercises the winner is the patient who finishes the exercise in the shortest time. In this exercise, and in all of the following competitive exercises, each user manages his/her own elements instances, although the visual representation and their location are the same the internal element is different. Thus, in this case any action taken on an element by a specific user does not involve any change in the elements managed by the other user. The design of the exercise is the same as it would be performed individually, so these exercise does not need any adaptation of the design interface.

\section{Competitive Cognitive Errors}

This type is similar to the previous one, in this case the winner is the patient who finishes the exercise with less cognitive errors. Thus, the design of the exercise is the same as it would be performed individually, so these exercise does not need any adaptation of the design interface.

\section{Competitive Physical Errors}

In this case the patient that finishes the exercise with less physical errors is the winner. As can be see, the design is the same as it would be performed individually and it does not need any adaptation of the design interface.

\section{Competitive Errors Count}

This is the last type of competitive exercise and in this case the system does not stablish any difference between cognitive o physical errors. In this case, the user who makes as many fails as the therapist establishes loses, or if the time has finished the winner is the patient that performs less errors. As in the other exercises, the interface used by the therapist to design this type of exercises is the same used to create exercises managed individually.

In general, the inclusion of these competitive exercises does not involve any relevant change in the de-sign interface. The therapist only need to define that this exercise could be carry out by the patient in a specific competitive mode.

\subsubsection{Collaborative exercise}

Unlike the competitive exercises, in the collaborative exercises there is no winner or it would be better to say that all the user win or lose at the same time. In this type of exercises, all the users work to achieve the same goal and it cannot be achieved individually. As we mentioned before, these exercises allow the therapist to analyze other relevant social aspect such us coordination and communication skills, so these capabilities are needed to carry out these exercises.

Two types of competitive exercises have been defined: Collaborative Share Objects; Collaborative simultaneous. These exercises will be presented below.

\section{Collaborative Share Objects}

In this type of exercise, patients share the elements displayed on the screen. All the users have the same elements and if one of them is selected by a specific patient the other cannot carry out any action on it. The objective of this type of exercises is that users perform the tasks in the shortest time than in the single user mode, or accomplish actions that a single user could not achieve, e.g. selecting two simultaneous elements located in opposite sides of the screen.

Miguel Oliver, José Pascual Molina, Antonio Fernández-Caballero and Pascual González Collaborative Computer-Assisted Cognitive Rehabilitation System
ADCAIJ: Advances in Distributed Computing and Articial Intelligence Journal Regular Issue, Vol. 6 N. 3 (2017), 57-74 elSSN: 2255-2863 - http://adcaij.usal.es (c) Ediciones Universidad de Salamanca - CC BY 


\section{Collaborative Simultaneous}

In this exercise both users must select at the same time the same element, since only the elements selected simultaneously will be taken into account for the system. This type of exercise is especially interesting to teach the patient how to perform the exercises, since the therapist our other expert user can carry out the same exercises at the same time as the patient can do. Thus, this type allows the therapist supervision of the exercise reducing the filling of insecurity of the patients in their exercise abilities, one relevant aspect that users of tele-rehabilitation systems have revealed (Cranen et al., 2012).

\section{Therapy Execution Environment}

These component control the execution of a specific exercise, allowing the participation of one or two users at the same time, and, in the last case, the users can be located in the same or different physical space. Thus, our system tries to provide a way to avoid the isolation of the patient if he/she carry out the exercises proposed by the therapist individually, without sharing his/her experiences with other people. Moreover, the design of the interface used by the patients is very simple, they only need to move some of their body part (those defined by the therapist) to accomplish the exercise and achieve the goal. In addition, if the patient makes an error, it is notified properly to explain the error and how it can solve.

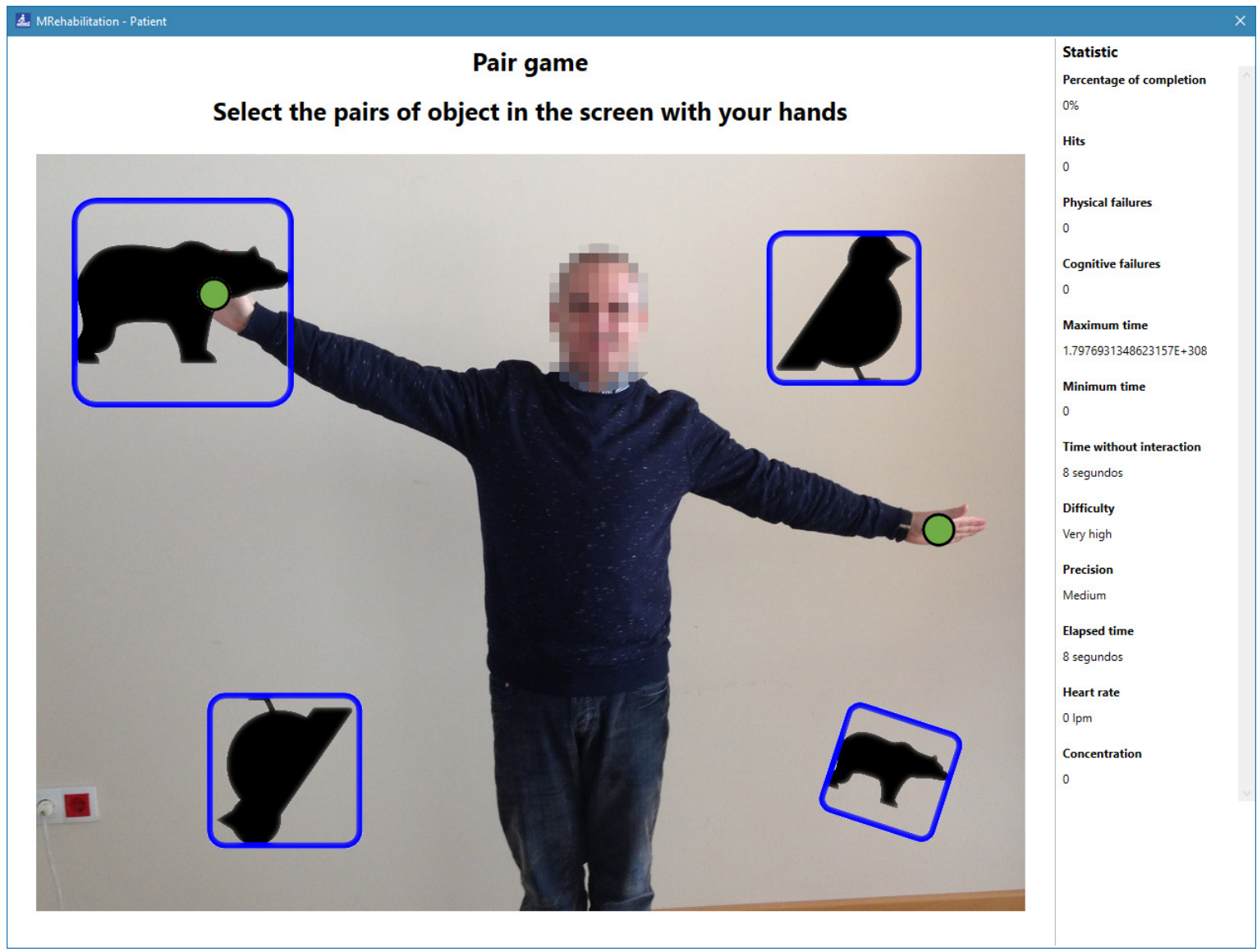

Figure 5. Patient performing an exercise

Miguel Oliver, José Pascual Molina,

Antonio Fernández-Caballero and Pascual González

Collaborative Computer-Assisted

Cognitive Rehabilitation System
ADCAIJ: Advances in Distributed Computing and Articial Intelligence Journal Regular Issue, Vol. 6 N. 3 (2017), 57-74 eISSN: 2255-2863 - http://adcaij.usal.es (c) Ediciones Universidad de Salamanca - cC BY 
The 'Therapy Execution Environment' takes data from therapy design created by the specialist in the 'Therapy Authoring' and the rules defined in the 'Rule Authoring' modules and, considering the information achieved from previous rehabilitation exercises and some physiological data obtained from some sensors that monitor the patient, the system determine the next exercise that the patient must accomplish, showing that exercise to the user.

At the beginning of the exercise, the user can observe, at the top of the monitor, the name, the goal and a description of how carry out the exercise, established by the therapist (see Figure 5). These will be read out loud by the system, which will help people with physical or cognitive impairments, and visually impaired people, to understand what they have to do in the exercise. This explanation must be sufficiently clear and precise for the user does not need any additional information for performing the full exercise. But depending on the type of exercise, i.e., if it is carry out by only one user or two users simultaneously the interface change. Now we are going to explain the interface displayed when the user carries out the exercise individually, the other case will be explained in the next section. Thus, if the user carries out the exercise individually, in the central part of the screen, the elements of the first Step created by the therapist and the figure of the patient appears. The image of the patient is captured by a Kinect sensor placed in front of him/her. On the right side of the interface, there are also highlighted the number of hits, cognitive and physical failures, the duration of the exercise, and the patient's physiological data (e.g., heart rate or concentration).

\subsection{Multiuser Execution}

All type of exercises described in section 3.1 (Pair Association, Multiple Association, and Categorization) can be executed in multiuser mode. So the therapist can create generic exercises and then, indicate whether the exercise should be performed individually or in any multiuser modes, i.e. competitive or collaborative. The use of multiuser exercises involves the patients in the therapy in a better way, increasing his/her motivation since the exercise include some aspects of a video game. Moreover, given the capability to be in contact with other user, this type of multiuser exercises improves relevant social aspects, reducing the patient isolate. Therefore, it produces relevant benefits in the rehabilitation process.

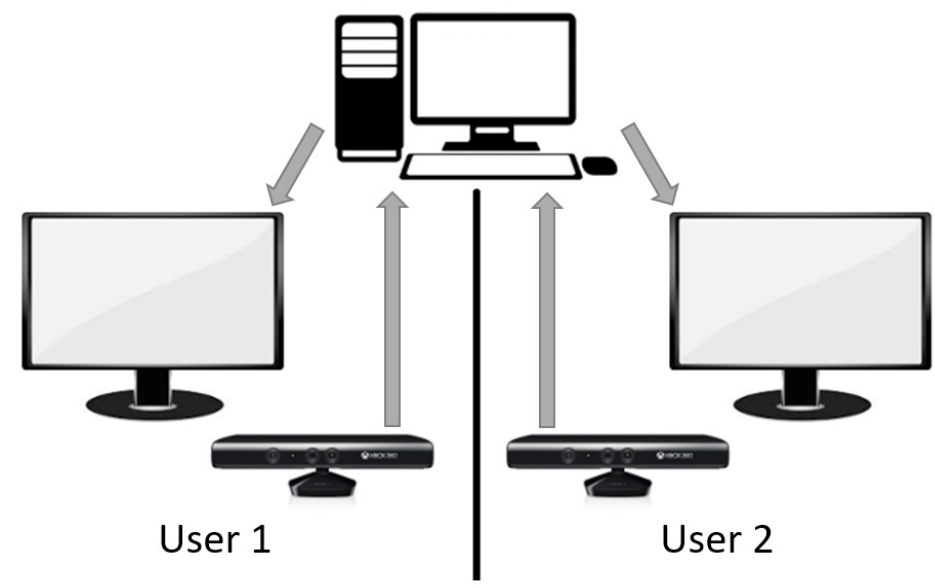

Figure 6. Locally multiuser system

Thus, after describing how the user can manage the system if he/she must carry out the exercises individually, we are going to explain the multiuser execution environment. As have been commented before, there are two types of multiuser exercises: Collaborative and Competitive. In addition, the user can do the exercise locally or remotely. The two modes need a sensor for each user, but the physical location of the users change.

If they do the exercise locally, the system architecture is like the presented before (see Figure 6), but we need two Kinect sensors, and two displays in the system. If each patient is located in a separate place, then we need

Miguel Oliver, José Pascual Molina,

Antonio Fernández-Caballero and Pascual González

Collaborative Computer-Assisted

Cognitive Rehabilitation System
ADCAIJ: Advances in Distributed Computing and Articial Intelligence Journal Regular Issue, Vol. 6 N. 3 (2017), 57-74 eISSN: 2255-2863 - http://adcaij.usal.es (C) Ediciones Universidad de Salamanca - cc BY 
use a more complex solution. In this case, the information of each sensor is sent to a computer (see Figure 7). Each computer manage the data achieved by its own Kinect and use this information for controlling the exercise execution. At the same time, each computer establishes a connection with the other to share the information of the join location of each user. Ones computers have all the data, they can display it in the interface and control the exercise execution. Through this system, rehabilitation could be offered to people located in different geographic areas.

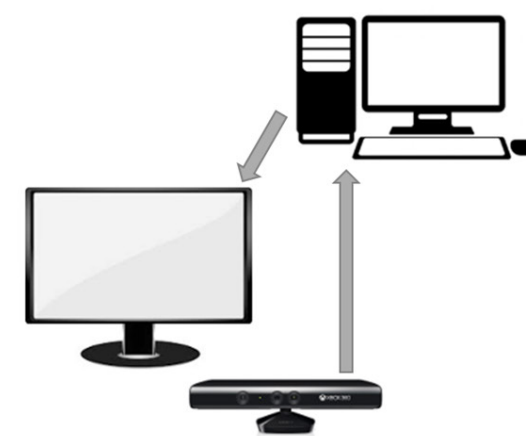

User 1

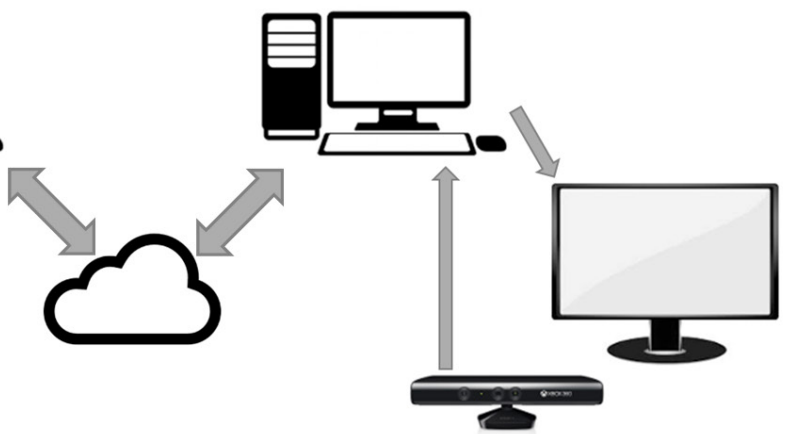

User 2

Figure 7. Remotely multiuser system

In multiuser exercises, the therapist can bring three types of awareness to patients. Depending on the mode selected by the therapist some information relevant to the patient appears or not. It is possible that some modes of awareness cannot be used with any collaborative modes, so it is the task of the therapist to study each type of exercise and its corresponding awareness when he/she designs it. Awareness types supported will be presented below.

\section{Awareness mode 1 (No visual information)}

This is the most restrictive type of awareness, since the user will not have visual information from the other patient. In this mode of awareness, the patient only has information on how he/she is performing the exercise. Although the patient is performing a multiuser exercise, he/she will only receive feedback from the other user at the end of the exercise. Despite this, there is a voice chat, which will be available in all types of awareness, with which users can communicate with each other.

An example of this type of awareness is shown in Figure 8. As can be seen, the interface presented is very similar to the interface used in single user rehabilitation exercises. The only part that changes with respect to the rest is the bottom right. This part shows a button that allows the user to activate or deactivate the voice chat.

With this type of awareness, we get the user to work in a very similar way as you would in the single user mode, but this user can communicate with another user, or with a specialist who guides him/her throughout the development of the exercise.

Miguel Oliver, José Pascual Molina,

Antonio Fernández-Caballero and Pascual González

Collaborative Computer-Assisted

Cognitive Rehabilitation System
ADCAIJ: Advances in Distributed Computing and Articial Intelligence Journal Regular Issue, Vol. 6 N. 3 (2017), 57-74 eISSN: 2255-2863 - http://adcaij.usal.es (c) Ediciones Universidad de Salamanca - cC BY 


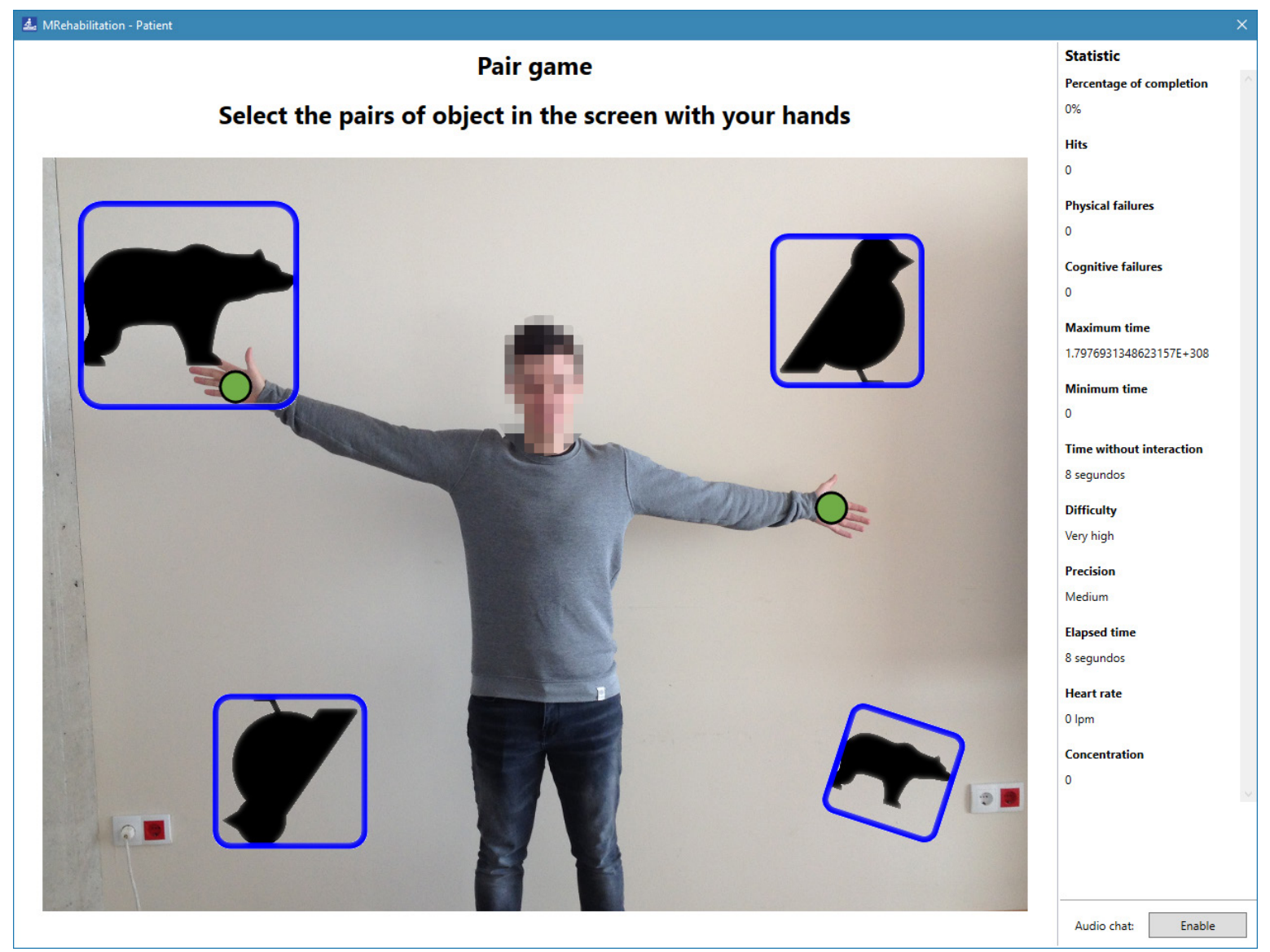

Figure 8. Awareness mode 1

\section{Awareness mode 2 (User's skeleton information)}

This type of awareness offers much more information than the previous awareness. The user receives information through the voice chat, as in the previous mode, but also can see information about the movements of the other user. The information that the user receives is the position at all points with which the other user must select the objects displayed in the exercise. These points are shown in superposition to the user's own, which allows him/her to understand in a faster way what movements the other patient is performing.

An example of this type of awareness is shown in Figure 9. As can be seen, the interface presented is very similar to the interface shown in the previous type of awareness. The only difference is that in addition to showing green dots representing the skeleton of the user, blue dots representing the partner's skeleton are also shown.

With this type of awareness, the user has a lot of information, since he/she can see in real time what kind of action the other patient is developing. Representing the points of the partner in the same screen where the user's own points are shown can cause momentary distractions, for this reason it is recommended to use this type of awareness in collaborative games. These games are designed for early stages of rehabilitation, where the user is more concerned with performing the exercise than in overcoming their marches. And therefore, collaboration with another user can help, even if this involves momentary distractions in performing the exercise. 


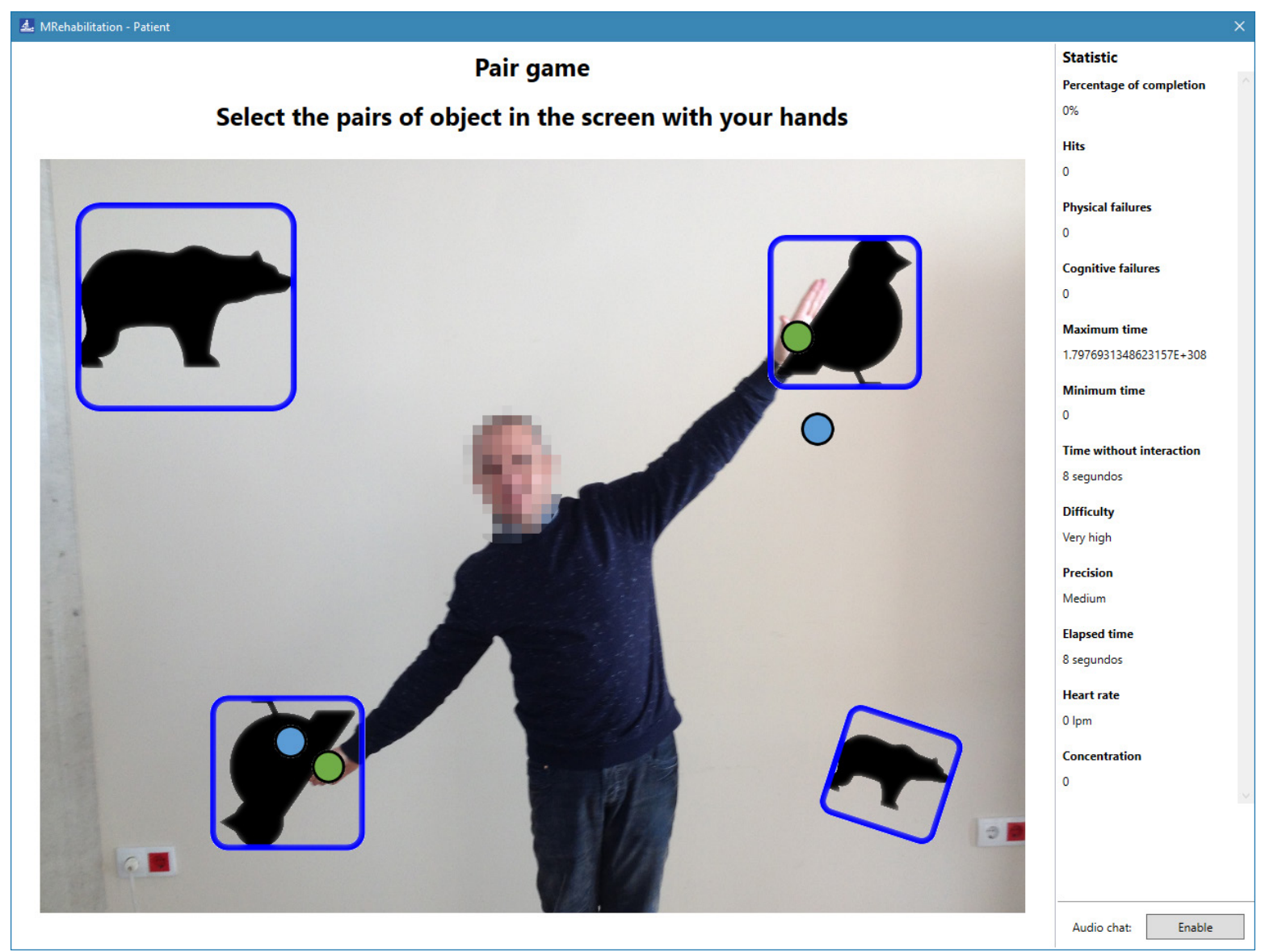

Figure 9. Awareness mode 2

\section{Awareness mode 3 (User's video information)}

In this type of awareness as much information as possible is available to the user. The user receives information through the voice chat, as in the awareness mode 0 , and also receives the position of the interest' points of the other patient as in the awareness mode 1. But instead of showing these points on the same screen as the patient, these points are shown on an additional screen. Also on this screen will also show the video of the other patient, so users can see how the other patient is performing the exercise.

An example of this type of awareness is shown in Figure 10. This interface changes with respect to the previous ones, since it is necessary to add a screen to show the video of the other patient. As can be seen in this figure, the left side of the interface remains the same as in previous interfaces. But in the right part a new window appears in which another user appears. In this window the patient can see at all times what the other user is doing, as well as what objects he/she is selecting and the positions he/she is performing.

With this type of awareness, the user has a lot of information, since he/she can see in real time the other patient. Because the screens showing the interest' points of both patients are separated, the patients do not suffer the momentary distractions that were discussed in the previous mode of awareness. This type of awareness is of special interest for competitive games, since users can see the other patient as well as the progress they have made. 


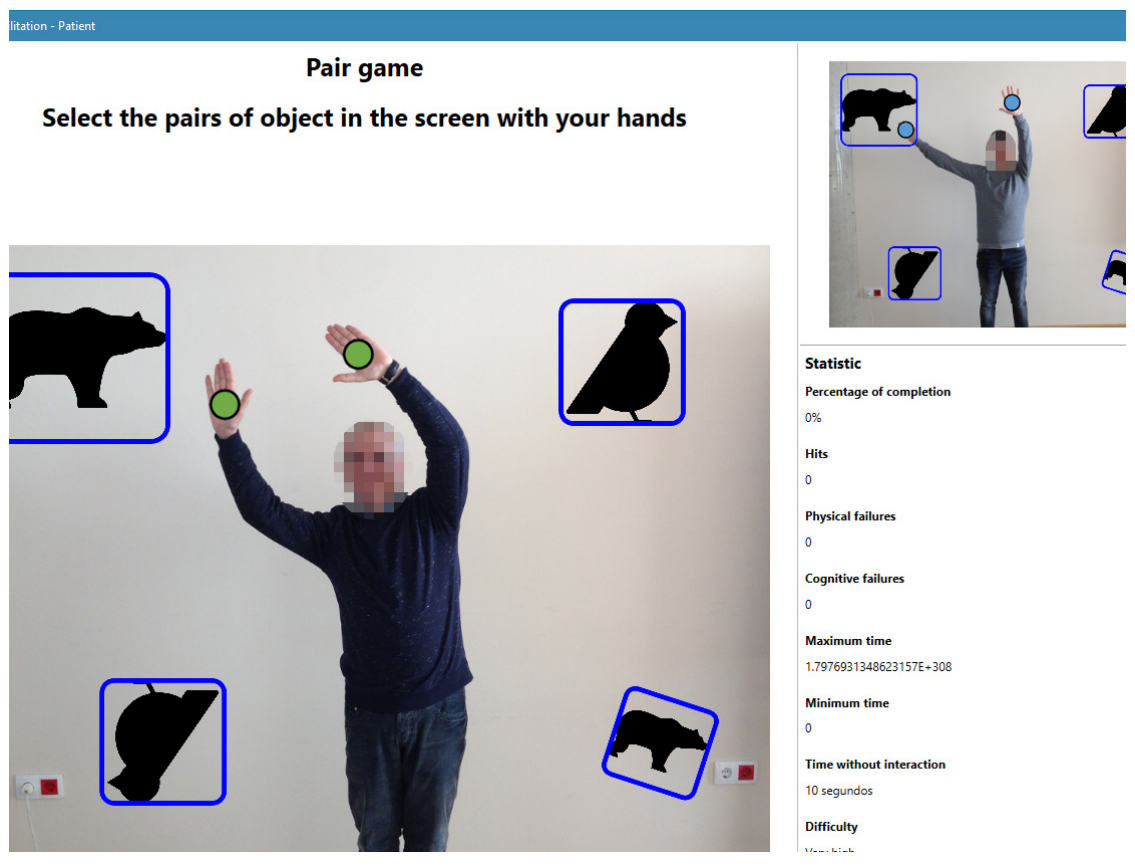

Figure 10. Awareness mode 3

\section{Discussion and Conclusions}

In this article, we have presented a multi-user cognitive rehabilitation system, mainly designed for avoiding isolation problems derived from the use of rehabilitation systems out of the specialized medical centers. Thus the main novelty of this proposal is the inclusion of some features to link together several patients, of as with his/her therapist. As we have noticed in the analysis of the state of the art, although we can find proposals that combine cognitive and physical rehabilitations, none of them include these features that allow the patient to collaborative o compete with another physically located in the same o in different place.

The system proposed includes different modalities to work with other users. In particular, it provides two types of modalities: collaborative or competitive. In addition, each modality has several types of exercises providing the therapist different ways to design the therapies and offering to the therapist a powerful tool to adapt these therapies for a specific patient. Finally, the execution environment includes several methods to present the information of the activity carried out by other users. Thus, the therapist can define different awareness, i.e. the patient has several modes to be aware of which action is carrying out by the other users. All these features, provide an environment where social activity could take place.

Thus, after analyzing different proposals in the rehabilitation domain and what kind of patients our system is focused on, we present our system and the main differences with our previous work (Oliver, M. et al., 2016) that is the base of this paper. We present the system architecture and describe all the components, detailing the new features that allow bringing in all the social aspects. Due the wide range of cognitive injuries that a person could have and the large number of exercises that exist to their treatments, it is impossible to design a system that covers all of them. Therefore, our system, although it is open to future extension, has focused on a small group of cognitive exercises (Pair Association, Multiple Association and Categorization). In addition, the therapists have the possibility to design their exercises from scratch and adapting them to a specific patient.

The development of the tool for the specialist has followed two fundamental principles. On the one hand, the tool is powerful and configurable enough to allow any type of exercise. On the other hand, it is simple enough so that the specialist is not overwhelmed by a very complex tool. This has been achieved by creating a generic tool that allows the user to perform any exercise. A wizard, which provides the most common parameters for

Miguel Oliver, José Pascual Molina,

Antonio Fernández-Caballero and Pascual González

Collaborative Computer-Assisted

Cognitive Rehabilitation System
ADCAIJ: Advances in Distributed Computing and Articial Intelligence Journal Regular Issue, Vol. 6 N. 3 (2017), 57-74 eISSN: 2255-2863 - http://adcaij.usal.es (c) Ediciones Universidad de Salamanca - cC BY 
each selected exercise, has been added. Thus, the therapist just need to put some elements in the work area. In the case of the patient's application, we have followed the principle of simplicity. Thus, the cognitive load of the application is the lowest, since the exercises start automatically and the system operation is very easy. This allows being use by people of different ages who do not have all their cognitive abilities.

In addition, to avoid the social isolation, loneliness, of people that use the rehabilitation systems in an individual manner, we have include some features that encourage the collaboration and the communication with other patients or therapists. These social exercises reduce the isolation, increase the motivation of the patients in carrying out their therapies and make these activities more fun and more exciting. Therefore, our system allows carrying out the exercises in a competitive or in a collaborative way with other patients. On one hand, in the competitive mode there are five types of exercises, and it is focused on promoting the competitiveness of users in their final stages of rehabilitation. On the other hand, the collaborative mode has two types of exercises Collaborative Simultaneous and Collaborative Share Objects. The first type allows the therapist to supervise and provide some support the patient when he/she is carrying out the exercise, reducing the filling of insecurity of the patients in their exercise abilities. In the second type, all the users share the same elements. The objective of this case is that users perform the tasks in the shortest time than in the single user mode, or accomplish actions that a single user could not achieve, e.g. selecting two simultaneous elements located in opposite sides of the screen. These activities allows the therapist to control other relevant social skill, such as coordination and communication. Finally, the therapy execution component include three awareness types. In this case, the user to carry out a specific task has different visual support levels. Thus, the user can watch a video of the activity other user or see the pointers of the skeleton joints that the user used to manage the exercise or only see his/her own activities.

Although in the design of the cognitive rehabilitation system has collaborate specialists that that help people with cognitive disabilities be retrained, as a future work, we are carrying out an evaluation of the system in a real environment. In this case, we are planning to evaluate our system in two different disadvantaged groups, people that sufferer an acquired brain injury and older people. Although, these collectives share certain common characteristics, we their knowledge and use of technology is not the same and, therefore, the acceptance of this system could be different.

\section{Acknowledgements}

This work was partially supported by Spanish Ministerio de Economía y Competitividad / FEDER under TIN2016-79100-R grant. Miguel Oliver holds an FPU scholarship (FPU13/03141) from the Spanish Government.

\section{References}

Ballesteros, S., Kraft, E., Santana, S., and Tziraki, C., 2015. Maintaining older brain functionality: a targeted review. Neuroscience \& Biobehavioral Reviews, 55, 453-477.

Bungalow Software, 2016. Speech \& Language Therapy Software. http://www.bungalowsoftware.com/.

Cagiltay, N. E., Ozcelik, E., and Ozcelik, N. S., 2015. The effect of competition on learning in games. Computers \& Education, vol. 87, pp. 35-41.

Chang, Y., Chen, S., and Huang, J., 2011. A Kinect-based system for physical rehabilitation: a pilot study for young adults with motor disabilities. Research in Developmental Disabilities, 32:6, 2566-2570.

Cranen, K., Drossaert, C. H., Brinkman, E. S., Braakman-Jansen, A. L., IJzerman, M. J., and Vollenbroek-Hutten, M. M., 2012. An exploration of chronic pain patients' perceptions of home telerehabilitation services. Health expectations, Vol. 15(4), pp. 339-350.

Desai, K., Bahirat, K., Ramalingam, S., Prabhakaran, B., Annaswamy, T., and Makris, U. E., 2016. Augmented reality-based exergames for rehabilitation. In Proceedings of the 7th International Conference on Multimedia Systems, ACM, article n 22.

Miguel Oliver, José Pascual Molina,

Antonio Fernández-Caballero and Pascual González

Collaborative Computer-Assisted

Cognitive Rehabilitation System
ADCAIJ: Advances in Distributed Computing and Articial Intelligence Journal Regular Issue, Vol. 6 N. 3 (2017), 57-74 eISSN: 2255-2863 - http://adcaij.usal.es (c) Ediciones Universidad de Salamanca - cC BY 
Freitas D., Da Gama A., Figueiredo L., Chaves T., Marques-Oliveira D., Teichrieb V., and Araujo C., 2012. Development and evaluation of a Kinect based motor rehabilitation game. Simposio Brasileiro de Jogos e Entretenimento Digital, 144-153.

González, C.S., Toledo, P., Padrón, M., Santos, E., and Cairos, M., 2013. TANGO: H: Creating Active Educational Games for Hospitalized Children. In Management Intelligent Systems, 135-142.

Gradior, 2016. IDES (spin-off of INTRAS Fundation) http://www.ides.es/gradior

Griffiths, M. D., 2005. Video games and health. British Medical Journal 331: 122-123.

Griffiths, M.D., Davies, M. N. O., and Chappell, D., 2004. Online computer gaming: a comparison of adolescent and adult gamers. Journal of adolescence 27 (1): 87-96.

Hernández, D., Villarrubia, G., Barriuso, A. L., Lozano, Á., \& Revuelta, J., 2015. Monitoring and analysis of vital signs of a patient through a multi-agent application system. Advances in Distributed Computing and Artificial Intelligence Journal, Vol. 4 n. 3

JClic, 2016. Ministry of Education of the Government of Catalonia (Spain) http://clic.xtec.cat/.

KineLabs, 2016. Office of the Government CIO. Government of the Hong Kong Special Administrative Region. http://www.ogcio.gov.hk/en/community/disabilities/kinelabs/kinelabs_download.htmKineLabs.

Learning Fundamentals, 2016. http://www.learningfundamentals.com/.

Montero, F., López-Jaquero, V., Navarro, E., and Sánchez, E., 2011. Computer-aided relearning activity patterns for people with acquired brain injury. Computers \& Education, 57(1), 1149-1159. doi: 10.1016/j. compedu.2010.12.008.

Oliver, M., González, P., Montero, F., Molina, J. P., and Fernández-Caballero, A., 2016. Smart Computer-Assisted Cognitive Rehabilitation for the Ageing Population. In Ambient Intelligence-Software and Applications-7th International Symposium on Ambient Intelligence (ISAmI 2016). Springer, pp. 197-205.

Oliver, M., Molina, J.P., Montero, F., González, P., and Fernández-Caballero, A., 2014. Wireless multisensory interaction in an intelligent rehabilitation environment. Ambient Intelligence-Software and Applications, 291, 193-200.

Pyae, A., Luimula, M., and Smed, J., 2015. Investigating the usability of interactive physical activity games for elderly: A pilot study. In 6th IEEE International Conference on Cognitive Infocommunications (CogInfo-Com), 2015, pp. 185-193

Rodríguez, A. C., Roda, C., Montero, F., González, P., and Navarro, E., 2016. An interactive fuzzy inference system for teletherapy of older people. Cognitive Computation, Vol. 8(2), pp. 318-335.

Sáenz de Urturi, Z., García, B., and Méndez, A., 2012. Kimentia: Kinect based tool to help cognitive stimulation for individuals with dementia. In e-Health Networking, Applications and Services (Healthcom), 2012 IEEE 14th International Conference on, pp. 325-328.

Sáenz de Urturi, Z., Garcia, B., and Méndez, A., 2014. Kinect-based virtual game for motor and cognitive rehabilitation: a pilot study for older adults. In Proceedings of the 8th International Conference on Pervasive Computing Technologies for Healthcare, pp. 262-265. ICST (Institute for Computer Sciences, Social-Informatics and Tele-communications Engineering).

Smith, S. T., and Schoene, D., 2012. The use of exercise-based videogames for training and rehabilitation of physical function in older adults: current practice and guidelines for future research. Aging Health, 8(3), 243-252.

Teki, 2016. Basque Health Service Department (Spain) and Accenture. http://www.osakidetza.euskadi.eus/ r85-ckcmpn05/es/contenidos/informacion/teki/es teki/teki.html.

Teruel, M.A., Oliver, M., Montero, F., Navarro, E., and González, P., 2015. Multisensory treatment of the hemispatial neglect by means of virtual reality and haptic techniques. Artificial Computation in Biology and Medicine, 469-478.

Toyra, 2016. Toledo National Hospital for Paraplegics (Spain) and Indra. http://www.toyra.org/.

Vera System, 2016. Reflexion Health http://reflexionhealth.com/theverasystem/.

VirtualRehab, 2016. Virtualware http://www.virtualrehab.info/.

Miguel Oliver, José Pascual Molina,

Antonio Fernández-Caballero and Pascual González

Collaborative Computer-Assisted

Cognitive Rehabilitation System
ADCAIJ: Advances in Distributed Computing and Articial Intelligence Journal Regular Issue, Vol. 6 N. 3 (2017), 57-74 eISSN: 2255-2863 - http://adcaij.usal.es (c) Ediciones Universidad de Salamanca - CC BY 